\section{Effects of colchicine on risk of cardiovascular events among patients with gout: as evidence accrues, is it time for a randomised trial?}

We read with great interest the paper by Solomon $e a^{1}$ on the effects of colchicine on risk of cardiovascular events and mortality among patients with gout. The authors should be commended on a well-planned and informative study, which, despite the non-randomised retrospective design, adds valuable evidence on a potential new role of this old drug in cardiovascular disease-a prospect which has come under scrutiny over the past few years. ${ }^{2}$

We would like to contribute a few comments and pose some questions. With regard to the reported apparent lack of a doseeffect relationship between colchicine and studied outcomes, from our experience with clinical studies of colchicine, ${ }^{3-6}$ gastrointestinal side effects-diarrhoea and nausea in particular -are important limiting factors for patient compliance and adherence to colchicine treatment. As a consequence, it is possible that patients who are prescribed high dosages of the drug end up discontinuing treatment earlier and taking a lower total dose and this may explain the authors' findings. In this frame of thought, we have noted that the authors do not provide data regarding daily doses used in the studied patient population. We believe it would be useful to have an idea of exposure to colchicine, in terms of median daily dose levels and treatment duration. Another point of interest would be the proportion of patients who took colchicine for an acute gout attack as opposed to those who used it as a preventive measure (eg, when started on a uric-acid-lowering treatment). If the number of patients in the latter group is not too small, it would be interesting to see whether there was an interaction between presence of an acute inflammatory state (ie, a gout attack) and the effectiveness of colchicine in reducing the risk of cardiovascular outcomes.

In spite of accumulating data, ${ }^{7}$ a large prospective randomised clinical trial of colchicine with enough power to evaluate hard outcomes is lacking and, considering the absence of industry interest, would probably be rather difficult to finance. In addition to the principal question of the efficacy of colchicine in reducing cardiovascular risk, such a study would have to address several other unresolved issues, including what is the optimal clinical setting for colchicine treatment, what dose levels should be employed and which patient populations really stand to gain benefit.

\section{Georgios Giannopoulos, Spyridon Deftereos}

Second Department of Cardiology, National and Kapodistrian University of Athens Medical School, Athens, Greece

Correspondence to Dr Georgios Giannopoulos, Second Department of Cardiology, University of Athens Medical School, Athens 12462, Greece; ggiann@med.uoa.gr, georgios.giannopolous@yale.edu

Competing interests None declared.

Provenance and peer review Not commissioned; internally peer reviewed.

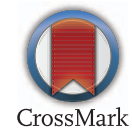

To cite Giannopoulos G, Deftereos S. Ann Rheum Dis 2016;75:e28.

Received 30 January 2016

Accepted 1 February 2016

Published Online First 18 February 2016

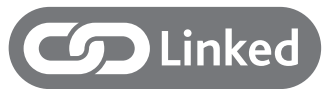

http://dx.doi.org/10.1136/annrheumdis-2016-209316

Ann Rheum Dis 2016;75:e28. doi:10.1136/annrheumdis-2016-209294

\section{REFERENCES}

1 Solomon DH, Liu CC, Kuo IH, et al. Effects of colchicine on risk of cardiovascular events and mortality among patients with gout: a cohort study using electronic medical records linked with Medicare claims. Ann Rheum Dis 2015; Published Online First 18 Nov 2015. http://dx.doi.org/10.1136/annrheumdis-2015-207984

2 Deftereos S, Giannopoulos G, Papoutsidakis N, et al. Colchicine and the heart: pushing the envelope. J Am Coll Cardiol 2013;62:1817-25.

3 Deftereos S, Giannopoulos G, Angelidis C, et al. Anti-inflammatory treatment with colchicine in acute myocardial infarction: a pilot study. Circulation 2015;132:1395-403.

4 Deftereos S, Giannopoulos G, Panagopoulou V, et al. Anti-inflammatory treatment with colchicine in stable chronic heart failure: a prospective, randomized study. JACC Heart Fail 2014;2:131-7.

5 Deftereos S, Giannopoulos G, Raisakis K, et al. Colchicine treatment for the prevention of bare-metal stent restenosis in diabetic patients. J Am Coll Cardiol 2013;61:1679-85.

6 Deftereos S, Giannopoulos G, Kossyvakis C, et al. Colchicine for prevention of early atrial fibrillation recurrence after pulmonary vein isolation: a randomized controlled study. J Am Coll Cardiol 2012;60:1790-6.

7 Verma S, Eikelboom JW, Nidorf SM, et al. Colchicine in cardiac disease: a systematic review and meta-analysis of randomized controlled trials. BMC Cardiovasc Disord 2015;15:96.

8 Giannopoulos G, Angelidis C, Papoutsidakis N, et al. Colchicine in coronary artery disease: an old acquaintance in new attire? Curr Med Chem 2015:22:4177-88. 